\title{
Diagnosing migraine
}

\author{
E Anne MacGregor ${ }^{1,2}$
}

${ }^{1}$ Associate Specialist, Barts Health NHS Trust, London, UK ${ }^{2}$ Associate Specialist, Centre for Neuroscience \& Trauma, Blizard Institute of Cell and Molecular Science, Barts and the London School of Medicine and Dentistry, London, UK

\section{Correspondence to} Dr E Anne MacGregor, Barts Sexual Health Centre, Kenton and Lucas Block, St Bartholomew's Hospital, London EC1A 7BE, UK; anne@annemacgregor.com

Received 18 May 2016 Accepted 22 August 2016

\section{CSLinked}

- http://dx.doi.org/10.1136/ jprhc-2016-101612

CrossMark

To cite: MacGregor EA. J Fam Plann Reprod Health Care 2016;42:280-286.

\begin{abstract}
Migraine is a common headache disorder, particularly in women. It usually starts during the teens and twenties, a time when many women are seeking contraception advice. Migraine without aura is the most prevalent type of migraine, affecting up to $70 \%$ of people with migraine, while the remainder experience attacks with and/or without aura. Aura is a phase of focal neurological symptoms, typically visual. An increasing body of evidence identifies aura as a marker of increased risk of ischaemic stroke and its presence is a contraindication to the use of combined hormonal contraception (CHC).

However, aura is often confused with more generalised premonitory visual symptoms of migraine that may precede attacks of migraine with and without aura, which are not associated with stroke risk. Diagnostic confidence is needed so that $\mathrm{CHC}$ is not withheld unnecessarily.
\end{abstract}

\section{INTRODUCTION}

Migraine is the commonest cause of severe episodic recurrent headache, affecting $19 \%$ of women and $11 \%$ of men worldwide. ${ }^{1}$ It is recognised by the World Health Organization (WHO) as the sixth leading cause globally of years lived with disability. ${ }^{2}$

Migraine incidence peaks between the ages of 20-24 years in women and 1519 years in men, ${ }^{3}$ with $90 \%$ of first attacks occurring before age 40 years. ${ }^{4}$ In both men and women, peak migraine prevalence is between 30 and 39 years, and peak disability is between 35 and 44 years. $^{6}$

The two most common types of migraine differ only in the presence or absence of an aura. Migraine without aura is most simply defined as disabling episodic headache attacks accompanied by sensitivity to light, nausea, and/or vomiting, lasting up to 72 hours. ${ }^{7}$ During attacks, activity is limited as it usually worsens the symptoms. In attacks of migraine with aura, the migraine headache is preceded by focal neurological

\section{Key message points}

Onset of migraine is usually during the teens and twenties, and so may occur coincidently with starting contraception.

- ID-Migraine ${ }^{\mathrm{TM}}$ is a screening tool for the three best predictors for diagnosing migraine without aura: photophobia, disability and nausea.

- The visual aura rating scale screens for the specific visual symptoms of migraine aura, which is a contraindication to the use of combined hormonal contraception.

symptoms. In both types of migraine, the person is symptom-free between attacks.

Types of migraine are not mutually exclusive within individuals. About 70\% of people with migraine have attacks of migraine without aura (formerly known as common or simple migraine); $20 \%$ have migraine with aura (formerly known as classical or focal migraine); and $10 \%$ have both types of attack. Less common is migraine aura without headache, which accounts for fewer than 1\% of attacks.

The changing hormonal environment in women is considered to be the main reason for the higher prevalence of migraine without aura in women during the reproductive years, with varying improvement or deterioration associated with menstruation, use of hormonal contraception, pregnancy, menopause, and use of hormonal drugs and hormone replacement therapy (HRT). In contrast, the prevalence of migraine with aura increases with age, occurring in around $13 \%$ of attacks in people with migraine aged 18-29 years, $20.1 \%$ between ages $40-49$ years, and $41 \%$ by age 70 years or older. $^{8}$

Around 25\% of women living in Great Britain aged 16-49 years use oral contraception, so there is a high likelihood that 
a proportion of these women will also have migraine (Figure 1). ${ }^{3} 9$ Correct diagnosis of the type of migraine is important since migraine with aura (but not migraine without aura) is associated with a two-fold increased risk of ischaemic stroke. ${ }^{10}{ }^{11}$ Use of combined oral contraceptives (COCs) is an independent risk factor for ischaemic stroke: odds ratio (OR) 1.56 [95\% confidence interval (CI) 1.61-1.89] for COCs containing $20 \mu \mathrm{g}$ ethinylestradiol and OR 1.75 (95\% CI $1.36-1.79)$ for $30 \mu \mathrm{g}$ COCs. ${ }^{12}$ Hence in the UK, USA and WHO Medical Eligibility Criteria, COCs are contraindicated in women with migraine aura. ${ }^{13-15}$ Progestogen-only methods do not increase risk of ischaemic stroke, ${ }^{12}$ and may benefit migraine with aura. ${ }^{16}$ Aura does not restrict use of physiological doses of estradiol in HRT, specifically transdermal estradiol, which is not associated with increased risk of ischaemic stroke. ${ }^{17}$

While the International Headache Society (IHS) has developed criteria for the diagnosis of migraine, ${ }^{7}$ these are more suited to research than to clinical practice. The aim of this review article is therefore to provide clinicians with quick and simple tools to diagnose migraine with and without aura.

\section{WHAT IS MIGRAINE?}

Migraine is more prevalent than diabetes, epilepsy and asthma combined. Although migraine is not lifethreating in itself, the severity and frequency of attacks can result in significant disability and reduced quality of life, even between attacks. ${ }^{18} 19$

Episodic attacks result from internal and environmental triggers that combine to reach the attack 'threshold', which is likely to be genetically determined (Figure 2). ${ }^{20}$ Crossing the threshold triggers

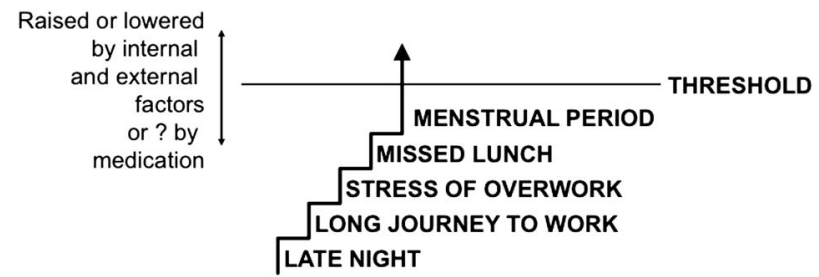

Figure 2 The threshold theory of migraine. Reproduced from MacGregor, ${ }^{20}$ by permission of SAGE publications.

changes in brain chemistry, which gradually resolve over the course of the attack. Prophylactic medication raises the migraine threshold and, depending on the type of medication, can treat some triggers, thus reducing the frequency of attacks; symptomatic treatment can interrupt the process of an attack, but cannot abort it.

\section{CLINICAL PHASES OF A MIGRAINE ATTACK}

An attack of migraine has five distinct clinical phases (Figure 3). ${ }^{21}$ The important point to note is that the migraine process is more than just aura and/or headache, but starts and ends with distinct and discrete phases.

\section{Premonitory phase}

Premonitory symptoms are distinct from, and unrelated to, the aura and can precede attacks of both migraine with and without aura by up to 48 hours. ${ }^{22}$ They are considered to be due to a transient hypothalamic disturbance. ${ }^{23} 24$ Typical symptoms include unusual tiredness, difficulty concentrating, neck stiffness, yawning, food cravings, blurred vision, and sensitivity to light, sound and smell. These are often mistaken for triggers, rather than symptoms that the

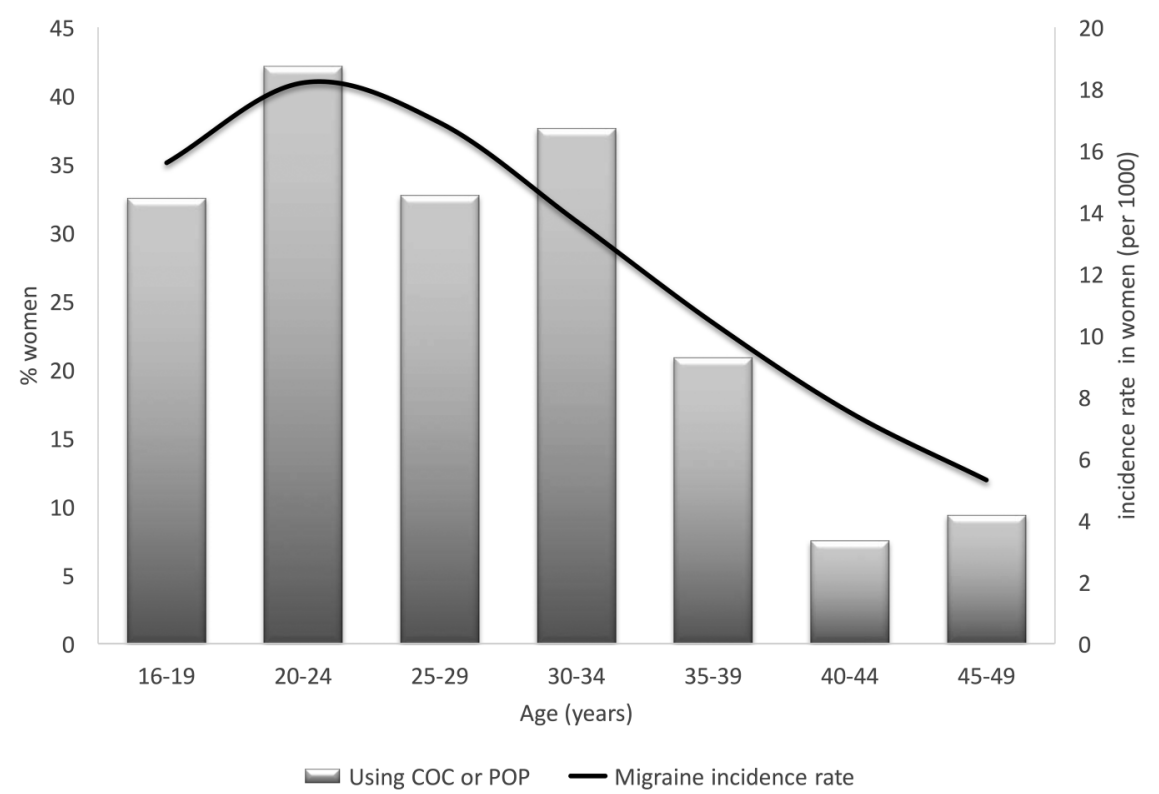

Figure 1 Use of oral contraception and 1-year prevalence of migraine in women aged 20-49 years. Data from Stewart et al.., ${ }^{3}$ and Lader. ${ }^{9}$ COC, combined oral contraception; POP, progestogen-only pill. 


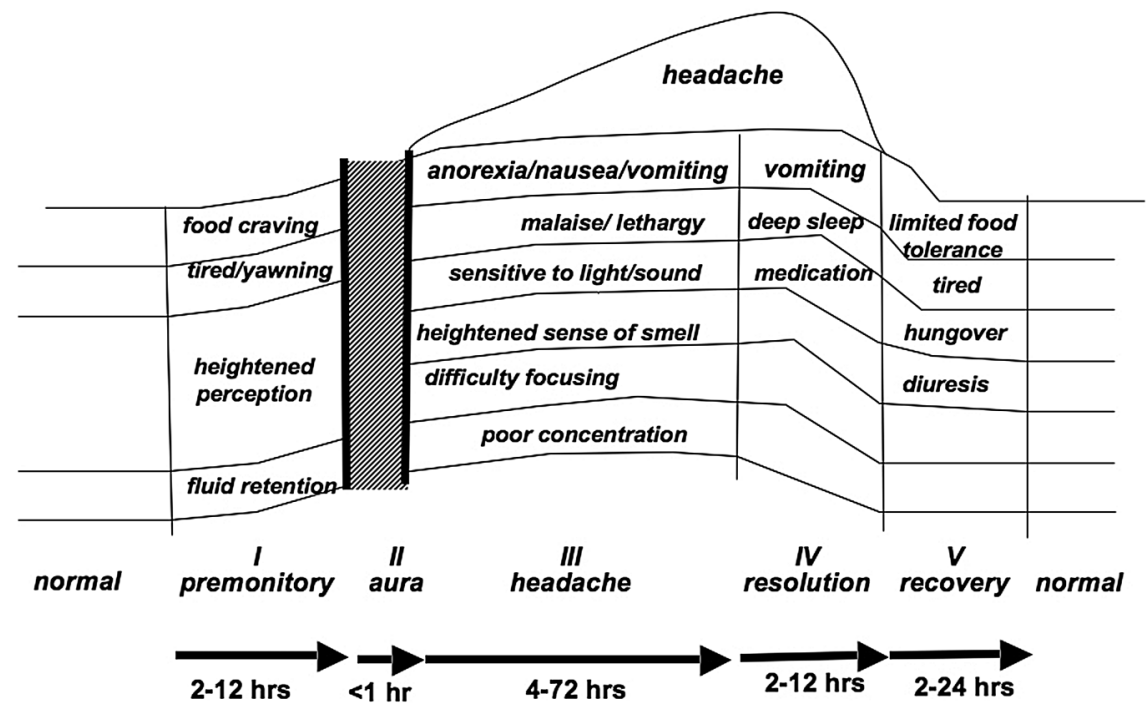

Figure 3 The five stages of a migraine attack. Adapted from Blau, ${ }^{21}$ by permission of Elsevier.

attack has already started. In her book Hotel $d u$ Lac, Anita Brookner eloquently describes premonitory symptoms which Edith experiences, the night before waking with a migraine headache:

"When ... she sat down to dinner, she was aware that the lights were brighter, the room more alive with personalities, the tables full ... she felt very tired, and thought that she would sleep soundly that night ... But sleep did not come easily ... When she awoke, rather later than usual, it was with the ancient and deadly foreknowledge that the day would be a write-off. Her broken night had left her with an aching head and an instinctive shrinking from both food and company. Minute noises seemed magnified: a trolley was wheeled vigorously along the corridor, and the high voices of the maids sounded unbearably piercing. "25

\section{Aura}

Aura, when present, may follow premonitory symptoms or may start without apparent warning. It is typically characterised by any combination of visual, hemisensory (sensory differences affecting only one side of the body, usually the arm, spreading up from the hand into the face), or language abnormalities, with each symptom developing over at least 5 minutes and lasting a maximum of 60 minutes. Other symptoms that can accompany migraine, such as vertigo or dizziness do not constitute aura.

Although some retrospective studies have suggested that migraine headache may develop during aura, the majority of prospective studies support that migraine headache follows aura. ${ }^{26-30}$ There may be a gap of several hours between resolution of aura and onset of migraine headache. ${ }^{31}$

Although there is no definitive proof, the mechanism underlying migraine aura is considered to be cortical spreading depression (CSD), a transient wave of depolarisation spreading across the visual cortex followed by suppression of brain activity. ${ }^{32}$ The rate of propagation of CSD is approximately $3 \mathrm{~mm}$ per minute, ${ }^{33}$ the same rate at which the clinical symptoms of aura spread. ${ }^{34}$ Animal models suggest that estrogen increases susceptibility to CSD, ${ }^{35}$ which might account for increased risk of migraine aura seen clinically during high estrogen states such as pregnancy, use of $\mathrm{CHC}$ and estrogen replacement therapy. $^{36}$

Aura has been vividly depicted in lay and medical literature over centuries and is well defined in this patient description:

"I first notice visual symptoms, starting with blind spots varying from perhaps part of a letter missing on a page, looking like a misprint, to somebody's chin missing, or the loss of half my field of vision. This culminates in pulsating zigzag lines around objects giving the impression of the scene being viewed through a shattered mirror. My speech is affected - I can't put a sentence together. I feel confused and disorientated. This is the most distressing part of the migraine attack and it lasts about 15 to 20 minutes. Then my vision restores itself at the same time as a sick, one-sided pain starts in my head."

Visual aura is present in over 98\% of auras. $273037-40$ The classic description is of a scotoma, an enlarging blank spot starting as a small spot and gradually increasing in size, which may be 'scintillating' - like the bright flashbulb effect from a camera. The curved margin of the scotoma can appear as zigzags or fortification spectra - a term coined in the late 18 th century because the visual disturbances resembled a fortified town surrounded by bastions. In a prospective study of 32 patients with migraine with aura, all patients reported either scintillating scotomas, or fortification spectra, or a combination of both. ${ }^{30}$ The uniformity of visual aura 
is evidenced by migraine art over centuries (Figures 4 and 5; further reading/information). ${ }^{4142}$

The aura usually starts at or near the centre of fixation, gradually spreading laterally, expanding at a rate of $3 \mathrm{~mm}$ per minute over a period of 5-60 minutes, typically around 20-30 minutes.

You do not need eyes to 'see' migraine aura, since it is emanating from the visual cortex, not from the eyes, so it will persist with the eyes closed. ${ }^{43}$ Visual aura symptoms are 'seen' in one half of the visual field in both eyes, although may subjectively be noticed only in one eye. Direct questioning can help elicit bilateral visual symptoms.

Sensory aura is often described as numbness or tingling affecting one $\mathrm{arm}^{39}$ This sensation often spreads proximally from the hand over several minutes to affect the mouth and tongue, as in the following description:

"The first symptom is when my eyes go. Then I get pins and needles in my hand which travels up my arm to my neck and into my mouth causing my tongue to go numb and my speech to be slightly affected. The headache then follows."

Speech can also be affected during migraine aura, with difficulty finding the correct words, or the wrong words being used like a 'word salad'. As with sensory symptoms, speech symptoms occur in combination with visual aura.

Aura should not be confused with symptoms of a stroke or transient ischaemic attack (TIA), which affect one side only, start suddenly, and do not have the scintillating and spreading features of migraine aura. In contrast to stroke and TIA, typical migraine aura does not affect the leg and there is no motor weakness.

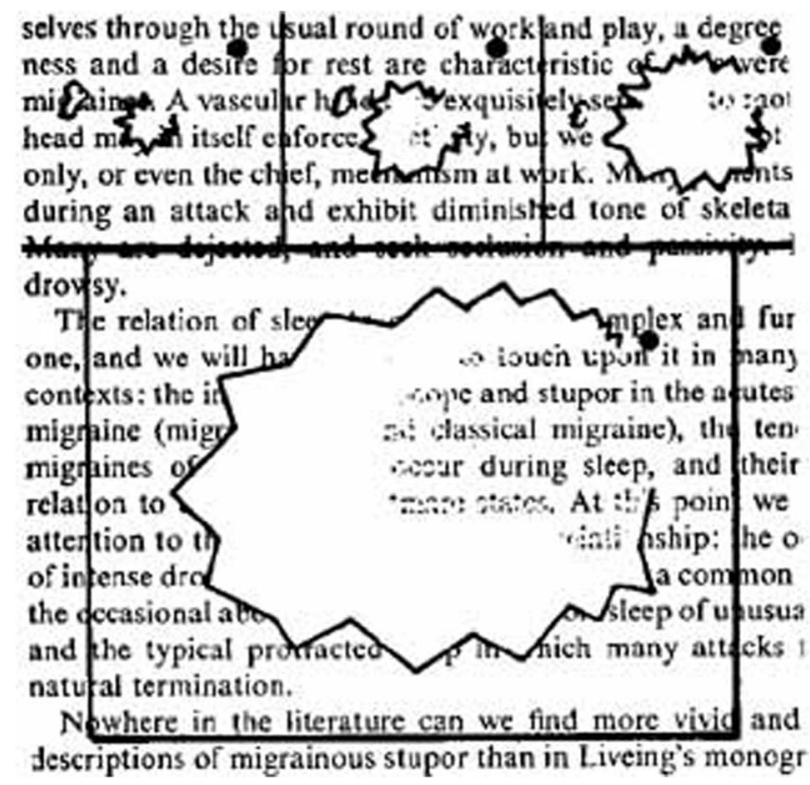

Figure 4 Depiction of an expanding scintillating scotoma and fortification spectra (by Sir William Richard Gowers). ${ }^{41}$

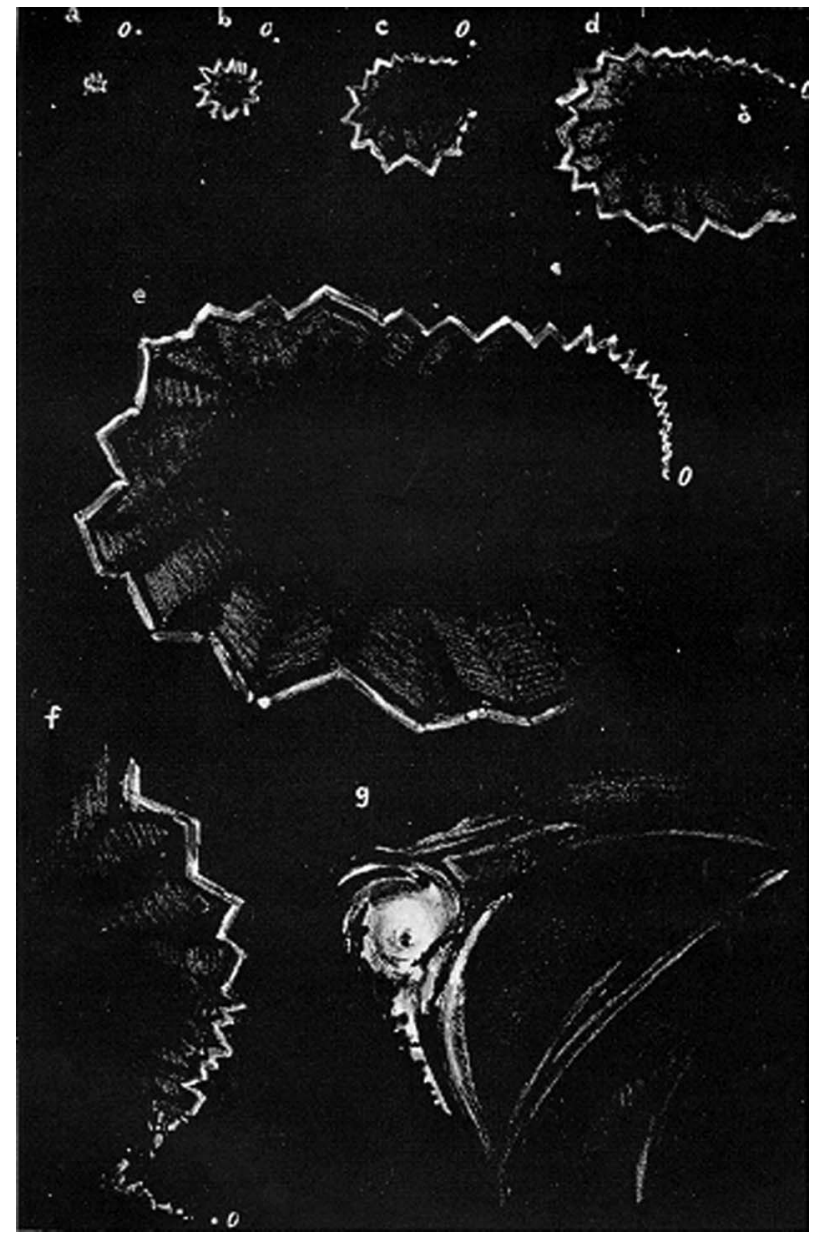

Figure 5 Depiction of an expanding scintillating scotoma and fortification spectra (by Hubert Airy). ${ }^{42}$

\section{Headache}

Migraine headache is typically unilateral but may be bilateral. It is accompanied by nausea or vomiting, photophobia and/or phonophobia. Activity is limited since headache is aggravated by movement, with a need for bed rest a common feature of severe attacks. As one person describes:

\begin{abstract}
"The pain begins at the front of my head and travels all over my head making the back of my head feel very heavy. I have to stay as still as I can otherwise it gets worse. I can't sit in a room with the lights on or the $T V$ as the light affects the strain on my eyes to my head. I feel very sick."
\end{abstract}

The pain is assumed to arise from the large cranial blood vessels and the dura mater, which are innervated by the trigeminal nerve. When activated, the trigeminal nerve transmits pain impulses to the trigeminal nucleus caudalis in the brain stem, which relays pain impulses to thalamus and up to the cerebral cortex, where the messages are decoded into the experience of pain. 
Resolution and recovery

The headache and accompanying symptoms resolve with time but can be attenuated by sleep and medication. In children, attacks often resolve with vomiting. The ensuing postdromal symptoms during the recovery phase can be as disabling as the headache itself, common symptoms being fatigue, cognitive impairment, and mood changes. A typical description is feeling "wrung through a mangle".

\section{DIAGNOSING MIGRAINE}

Types of migraine are not mutually exclusive and around $30 \%$ of people with migraine with aura also have attacks without aura, ${ }^{37} 4044$ with the pattern changing over time. Women often experience a flurry of attacks of migraine with aura around puberty and then only have attacks without aura for many years. In later life, migraine aura without headache is more prevalent as headache becomes less of a feature with advancing age. ${ }^{40} 44$ Most people with attacks of migraine aura without headache have or have had migraine aura with headache. ${ }^{30} 39$

\section{Diagnosing migraine without aura}

ID-Migraine ${ }^{\mathrm{TM}}$ is a valid and reliable symptom-based screener for migraine without aura that has been developed for use in primary care. ${ }^{45}$ It is based on the three best predictors for diagnosing migraine without aura, namely photophobia, disability and nausea; patients who report two of these symptoms have an $81 \%$ probability of having migraine and three symptoms increases the probability to $93 \%$. A simple acronym for the ID-Migraine questions is 'PIN' (Box 1). ${ }^{46}$

\section{Diagnosing migraine with aura}

Since visual aura occurs in isolation or in association with sensory aura or speech disturbance, diagnosis of aura can be made based on the visual symptoms alone. ${ }^{27}$

Questioning needs to be specific, since visual symptoms occur during each stage of migraine, with blurred vision reported by $28 \%$ of people with migraine experiencing premonitory symptoms and $35 \%$ during the headache. However, non-aura visual symptoms differ from aura by their lack of gradual development and longer duration. For example, non-aura visual symptoms are often characterised by flickering lights or 'phosphenes' lasting less than 5 minutes and which may recur at intervals, ${ }^{47} 48$ or general blurring of vision lasting more than 60 minutes. ${ }^{47}$ So a report of "Seeing spots of light flashing before my eyes" before and during the headache is not migraine aura.

The question "Have you ever had visual disturbances lasting 5-60 minutes followed by headache?" is a useful screener as studies show that it correctly identified $74 \%$ of patients diagnosed with migraine
Box 1 'PIN' for the diagnosis of migraine without aura with ID-Migraine $\mathrm{TM}^{45} 46$

\begin{tabular}{|c|c|}
\hline Photophobia & $\begin{array}{l}\text { Does light bother you when you have a } \\
\text { headache? }\end{array}$ \\
\hline Impairment & $\begin{array}{l}\text { Do you experience headaches that impair } \\
\text { your ability to function? }\end{array}$ \\
\hline laus & $\begin{array}{l}\text { Do you feel nauseated or sick to } \\
\text { stomach when you have a headache? }\end{array}$ \\
\hline
\end{tabular}

Table 1 Visual aura rating scale (VARS) score for diagnosis of migraine aura ${ }^{47}$

\begin{tabular}{ll}
\hline Visual symptom characteristic & $\begin{array}{l}\text { Risk } \\
\text { score }\end{array}$ \\
\hline Duration 5-60 minutes & 3 \\
Develops gradually $\geq 5$ minutes & 2 \\
Blank spot (scotoma) & 2 \\
Zig-zag line (fortification spectra) & 2 \\
Affects the same side of both eyes (homonymous & 1 \\
hemianopia) & \\
\hline Maximum VARS score & 10 \\
Migraine with aura diagnosis & $\geq 5$ \\
\hline
\end{tabular}

aura by interview and correctly identified $91 \%$ of patients who did not have migraine aura. ${ }^{49}$ However, it is not specific to aura and may over-diagnose aura in a patient with migraine without aura.

A more sensitive and specific tool is the visual aura rating scale (VARS) for migraine aura diagnosis, which is based on the IHS's diagnostic criteria. ${ }^{47}$ The VARS score is the weighted sum of the presence of five visual symptom characteristics: duration 5-60 min (3 points), develops gradually over at least $5 \mathrm{~min}$ (2 points), scotoma (2 points), zig-zag lines ( 2 points) and unilateral (1 point) (Table 1 ). A VARS score of $\geq 5$ out of a maximum score of 10 points has a sensitivity of 96\% (95\% CI 92-99\%) and a specificity of 98\% (95\% CI 95-100\%) for migraine aura.

Additional tips to confirm the diagnosis of aura are to show patients pictures of aura to assess similarities with their own symptoms. As aura is so specific, a vagueness when describing symptoms makes aura unlikely. Asking patients to draw their symptoms is confirmatory as patients with aura will draw zig-zag lines. Further confirmation is persistence of visual symptoms with the eyes closed.

\section{Diagnosing migraine aura without headache}

Aura without headache is more prevalent with increasing age and there is usually a current or past history of migraine with aura. Aura is the same whether or not it is accompanied by headache and carries the same risk of ischaemic stroke as migraine with aura. The VARS score does not depend on presence of 
headache so VARS can be used to screen for aura without headache.

\section{Case study}

A 17-year-old woman was referred for contraceptive advice. She was taking the desogestrel progestogenonly pill but was unhappy with this method because of frequent unscheduled bleeding. The referral information stated that she had migraine with aura since the age of 15 years, so her preferred choice of $\mathrm{CHC}$ was contraindicated. The stated history was that the patient "lost her vision" and then developed a headache associated with nausea and vomiting, which resolved with sleep.

On direct questioning, the visual symptoms started a couple of hours before the headache and lasted for the duration of the attack. They were worse if the accompanying headache was severe. She experienced blurred vision and difficulty focusing, which resolved if she closed her eyes. When shown pictures of typical aura and asked if she experienced anything similar, her response was 'No'.

This shows the importance of asking the right questions regarding visual symptoms to make the correct diagnosis. In this case, the duration of visual symptoms was longer than 60 minutes, they were present both before and during the headache, and the symptoms were non-specific. The correct diagnosis was migraine without aura, with no contraindication to $\mathrm{CHC}$.

\section{WHAT TO DO WHEN IN DOUBT}

There are always times when the story is unclear and it is impossible to be completely certain about the diagnosis. If in doubt, progestogen-only or nonhormonal contraception can be used while the woman keeps a diary of symptoms for subsequent review.

\section{CONCLUSIONS}

Migraine aura, with or without migraine headache, is an independent risk factor for ischaemic stroke and contraindicates use of CHC. Migraine without aura is not a risk factor for ischaemic stroke and CHC may therefore be used.

Visual symptoms are common in migraine, both with and without aura, which can lead to diagnostic confusion. Over-diagnosis of aura results in underprescription of CHC. Simple screening tools such as ID-Migraine for migraine without aura or VARS for migraine aura can aid diagnosis in the clinical setting, enabling correct identification of women who can and cannot be offered the option of CHC.

Acknowledgements The author is grateful to Alison Frith and Manori Bandara for their comments on the manuscript.

Competing interests In the last 3 years the author has acted as a paid consultant to, and/or her department has received research funding from, Bayer Healthcare, Consilient Health, and Menarini.
Provenance and peer review Not commissioned; externally peer reviewed.

\section{REFERENCES}

1 Vos T, Flaxman AD, Naghavi M, et al. Years lived with disability (YLDs) for 1160 sequelae of 289 diseases and injuries 1990-2010: a systematic analysis for the Global Burden of Disease Study 2010. Lancet 2012;380:2163-2196.

2 Global Burden of Disease Study 2013 Collaborators. Global, regional, and national incidence, prevalence, and years lived with disability for 301 acute and chronic diseases and injuries in 188 countries, 1990-2013: a systematic analysis for the Global Burden of Disease Study 2013. Lancet 2015;386:743-800.

3 Stewart WF, Wood C, Reed ML, et al. Cumulative lifetime migraine incidence in women and men. Cephalalgia 2008;28:1170-1178.

4 Stewart WF, Linet MS, Celentano DD, et al. Age- and sex-specific incidence rates of migraine with and without visual aura. Am J Epidemiol 1991;134:1111-1120.

5 Lipton RB, Bigal ME, Diamond M, et al. Migraine prevalence, disease burden, and the need for preventive therapy. Neurology 2007;68:343-349.

6 Institute for Health Metrics and Evaluation (IHME). GBD Compare. Seattle, WA: IHME, University of Washington, 2015. http://vizhub.healthdata.org/gbd-compare [accessed 11 May 2016].

7 Headache Classification Committee of the International Headache Society (IHS). The International Classification of Headache Disorders, 3rd edition (beta version). Cephalalgia 2013;33:629-808.

8 Bigal ME, Liberman JN, Lipton RB. Age-dependent prevalence and clinical features of migraine. Neurology 2006;67: 246-251.

9 Lader D. Opinions Survey Report No. 41. Contraception and Sexual Heath, 2008/09. 2009. http://www.ons.gov.uk/ons/rel/ lifestyles/contraception-and-sexual-health/2008-09/2008-09.pdf [accessed 11 May 2016].

10 Schürks M, Rist PM, Bigal ME, et al. Migraine and cardiovascular disease: systematic review and meta-analysis. BMJ 2009;339:b3914.

11 Spector JT, Kahn SR, Jones MR, et al. Migraine headache and ischemic stroke risk: an updated meta-analysis. Am J Med 2010;123:612-624.

$12 \mathrm{Xu}$ Z, Li Y, Tang S, et al. Current use of oral contraceptives and the risk of first-ever ischemic stroke: a meta-analysis of observational studies. Thromb Res 2015;136:52-60.

13 Faculty of Sexual and Reproductive Healthcare. UK Medical Eligibility Criteria for Contraceptive Use (UKMEC 2016). 2016. https://www.fsrh.org/standards-and-guidance/ uk-medical-eligibility-criteria-for-contraceptive-use/ [accessed 15 August 2016].

14 Curtis KM, Tepper NK, Jatlaoui TC, et al. U.S. Medical Eligibility Criteria for Contraceptive Use, 2016. MMWR Recomm Rep 2016;65:1-103.

15 World Health Organization. Medical Eligibility Criteria for Contraceptive Use (5th edn). 2015. http://www.who.int/ reproductivehealth/publications/family_planning/MEC-5/en/ [accessed 15 August 2016].

16 Nappi RE, Sances G, Allais G, et al. Effects of an estrogen-free, desogestrel-containing oral contraceptive in women with migraine with aura: a prospective diary-based pilot study. Contraception 2011;83:223-228. 
17 Sarri G, Davies M, Lumsden MA, et al. Diagnosis and management of menopause: summary of NICE guidance. BMJ 2015;351:h5746.

18 MacGregor EA, Brandes J, Eikermann A, et al. Impact of migraine on patients and their families: the Migraine And Zolmitriptan Evaluation (MAZE) survey - Phase III. Curr Med Res Opin 2004;20:1143-1150.

19 Steiner TJ, Scher AI, Stewart WF, et al. The prevalence and disability burden of adult migraine in England and their relationships to age, gender and ethnicity. Cephalalgia 2003;23:519-527.

20 MacGregor EA. "Menstrual" migraine: towards a definition. Cephalalgia 1996;16:11-21.

21 Blau JN. Migraine: theories of pathogenesis. Lancet 1992;339:1202-1207.

22 Giffin NJ, Ruggiero L, Lipton RB, et al. Premonitory symptoms in migraine: an electronic diary study. Neurology 2003;60:935-940.

23 Alstadhaug KB. Migraine and the hypothalamus. Cephalalgia 2009;29:809-817.

24 Denuelle M, Fabre N, Payoux P, et al. Hypothalamic activation in spontaneous migraine attacks. Headache 2007;47:1418-1426.

25 Brookner A. Hotel du Lac. London, UK: Penguin, 1994.

26 Russell MB, Iversen HK, Olesen J. Improved description of the migraine aura by a diagnostic aura diary. Cephalalgia 1994;14:107-117.

27 Russell MB, Olesen J. A nosographic analysis of the migraine aura in a general population. Brain 1996;119(Pt 2): 355-361.

28 Olesen J, Friberg L, Olsen TS, et al. Timing and topography of cerebral blood flow, aura, and headache during migraine attacks. Ann Neurol 1990;28:791-798.

29 Jensen K, Tfelt-Hansen P, Lauritzen M, et al. Classic migraine. A prospective recording of symptoms. Acta Neurol Scand 1986;73:359-362.

30 Cologno D, Torelli P, Manzoni GC. A prospective study of the headache phase in 32 migraine with aura patients. Cephalalgia 2002;22:411-415.

31 Blau JN. Classical migraine: symptoms between visual aura and headache onset. Lancet 1992;340:355-356.

32 Charles AC, Baca SM. Cortical spreading depression and migraine. Nat Rev Neurol 2013;9:637-644.

33 Hadjikhani N, Sanchez Del Rio M, Wu O, et al. Mechanisms of migraine aura revealed by functional MRI in human visual cortex. Proc Natl Acad Sci USA 2001;98:4687-4692.

34 Lashley KS. Patterns of cerebral integration indicated by the scotomas of migraine. Arch Neurol Psychiatry 1941;46:331-339.

35 Bolay H, Berman NE, Akcali D. Sex-related differences in animal models of migraine headache. Headache 2011;51:891-904.
36 MacGregor EA. Oestrogen and attacks of migraine with and without aura. Lancet Neurol 2004;3:354-361.

37 Eriksen MK, Thomsen LL, Andersen I, et al. Clinical characteristics of 362 patients with familial migraine with aura. Cephalalgia 2004;24:564-575.

38 Kallela M, Wessman M, Färkkilä M, et al. Clinical characteristics of migraine in a population-based twin sample: similarities and differences between migraine with and without aura. Cephalalgia 1999;19:151-158.

39 Cologno D, Torelli P, Cademartiri C, et al. A prospective study of migraine with aura attacks in a headache clinic population. Cephalalgia 2000;20:925-930.

40 Eriksen MK, Thomsen LL, Olesen J. New international classification of migraine with aura (ICHD-2) applied to 362 migraine patients. Eur J Neurol 2004;11:583-591.

41 Gowers WR. Lectures on Diseases of the Nervous System, Second Series. Subjective Sensations of Sight and Sound, Abiotrophy, and Other Lectures. London, UK: J \& A Churchill, 1904:18-41.

42 Airy H. On a distinct form of transient hemiopsia. Phil Trans Roy Soc 1870;160:247-264.

43 Peatfield RC, Rose FC. Migrainous visual symptoms in a woman without eyes. Arch Neurol 1981;38:466.

44 Cologno D, Torelli P, Manzoni GC. Migraine with aura: a review of 81 patients at 10-20 years' follow-up. Cephalalgia 1998;18:690-696.

45 Lipton RB, Dodick D, Sadovsky R, et al. A self-administered screener for migraine in primary care: the ID Migraine validation study. Neurology 2003;61:375-382.

46 Dodick DW. Pearls: headache. Semin Neurol 2010;30:74-81.

47 Eriksen MK, Thomsen LL, Olesen J. The Visual Aura Rating Scale (VARS) for migraine aura diagnosis. Cephalalgia 2005;25:801-810.

48 Cologno D, Torelli P, Manzoni GC. Transient visual disturbances during migraine without aura attacks. Headache 2002;42:930-933.

49 Gervil M, Ulrich V, Olesen J, et al. Screening for migraine in the general population: validation of a simple questionnaire. Cephalalgia 1998;18:342-348.

\section{FURTHER READING/INFORMATION}

1 Podoll K, Robinson D. Migraine Art: The Migraine Experience from Within. Berkeley, CA: North Atlantic Books, 2008.

2 Schott GD. Exploring the visual hallucinations of migraine aura: the tacit contribution of illustration. Brain 2007;130(Pt 6): 1690-1703.

3 Wilkinson M, Robinson D. Migraine art. Cephalalgia 1985;5:151-157.

4 For a depiction of visual aura see: https://www.youtube.com/ watch?v=G8P_ZTJqv8g

\section{JOURNAL REVIEW WRITERS}

The Journal regularly reviews articles from related publications and is looking to recruit more volunteers to compile these short reviews. For further information and/or to offer your services (at most once or twice a year) please e-mail your contact details to the Journal Editorial Office together with a note of any special interests and/or expertise to assist us in allocating relevant articles to individual reviewers. For further information on this role please contact the Journal Editorial Office at journal@fsrh.org. 